\title{
MODELING OF VACUUM ARC REMELTING OF ALLOY 718 INGOTS
}

\author{
Ashish D. Patel ${ }^{1}$, Ramesh S. Minisandram ${ }^{2}$, David G. Evans ${ }^{3}$ \\ ${ }^{1}$ Carpenter Technology Corporation, 101 W Bern St. Reading PA 19601 \\ ${ }^{2}$ ATI Allvac, 2020 Ashcraft Avenue, Monroe, NC 28111 \\ ${ }^{3}$ Special Metals Corporation, 4317 Middle Settlement Road, New Hartford, NY 13413
}

Keywords: VAR, Pool profile, Defects

\begin{abstract}
Vacuum Arc Remelting (VAR) is typically the final melting process in the production of a wide range of alloys including superalloys, titanium, zirconium and specialty steels. During this process, a DC arc is struck under vacuum between a consumable electrode and a water-cooled copper crucible. The heat from the arc melts the electrode and molten metal droplets from the electrode solidify in the crucible to form an ingot. The purpose of VAR is to cast a sound, segregation free ingot. The soundness of the final structure and tendency for defect formation are determined by the pool profile and ingot solidification patterns during the process. These, in turn, depend on the melting parameters, which change as the ingot freezes. A carefully developed physics-based numerical model is useful in analyzing $a$ priori the effect of melt parameters on the molten metal pool in the ingot. The purpose of this paper is to discuss the key features of such a model, and examine the effect of melting parameters on the pool profile. In addition, the effect of a molten metal pool perturbation during a power interruption and a melt rate cycle is examined for a $0.5 \mathrm{~m}$ (20-inch) diameter ingot. Finally, the computed temperature distribution and flow field is used to predict the melting time for particles that fall into the molten pool and the likelihood of freckle formation in an alloy 718 VAR ingot.
\end{abstract}

\section{Introduction}

Vacuum Arc Remelting (VAR) is a process in which an electrode is melted in vacuum by the heat from a DC arc. Metal droplets from the electrode drip into a water-cooled copper crucible forming an ingot topped by a molten pool [1], as seen in Figure 1. The intent is to produce a sound ingot with uniform cleanliness and chemical homogeneity. The process is the final melting process for most nickel base superalloys and titanium alloys. It is used wherever the intended application of the material must meet the most stringent criteria, such as rotating and structural parts in aeroengines and airframes.

The VAR process involves the complex interaction of many physical and solidification phenomena. Direct measurement of the critical aspects of the process is difficult due to it taking place under vacuum in a closed chamber at extreme temperatures (most alloys under consideration melt in the range of 1600-1800K). This combination of circumstances has driven efforts to model the many aspects of the process and provides an insight into the effect of melting parameters on the molten pool and the solidification region of the ingot.

In 1989, the specialty metals producers and Sandia National Laboratories founded the Specialty Metals Processing Consortium (SMPC) with the goal of conducting advanced research in the area of process modeling and controls [2]. Examples of other longterm continuing efforts outside of the SMPC have included cooperative efforts between the University of Birmingham and Imperial College in Britain $[3,4]$ and co-operative efforts between the Ecole-de-Mines de Nancy and French Industry [5,6]. These illustrate the many aspects of the VAR process that have to be considered in order to produce an acceptable product. The SMPC effort in VAR modeling has focused on studying the pool shapes in nickel and titanium based alloys. The British effort has concentrated on nickel base alloys, particularly alloy 718 . The French effort has concentrated on titanium and zirconium based alloys considering such aspects as macro-segregation of critical elements like oxygen.

The models are now maturing to the point where they are becoming tools used by process engineers to analyze practical day-to-day melt concerns. Illustrations of how a comprehensive VAR model is calibrated and used in this manner will be illustrated in the balance of this paper. This work focuses on efforts to model the VAR process with respect to $0.5 \mathrm{~m}$ (20") diameter alloy 718 . In addition, simple defect criteria derived from the model predictions are presented.

\section{Brief Description of the Model}

The VAR model has been developed over the past decade by The Specialty Metals Processing Consortium (SMPC), and exists in large part due to the effort of the late Dr. Lee Bertram. Various input parameters to the model and model predicted parameters are shown in Figure 2. The mathematical model is a fully transient two-dimensional explicit finite difference code using the streamfunction-vorticity formulation. It solves the equations governing heat transfer, fluid flow and electromagnetic fields in a cylindrical co-ordinate system. The temperature distribution is obtained from the solution of the thermal energy equation. The flow field in the molten pool is obtained from the solution of the streamfunction-vorticity equation. The electromagnetic field is obtained by solving Laplace's equation for the scalar potential. The governing equations and particulars regarding the boundary conditions have been published previously [7-11]. 


\section{Effect of Melting Parameters on Pool Profile}

The pool that is formed during VAR is determined by the balance between the energy supplied to the ingot from the melting electrode and the arc, and the energy removed from the surfaces of the ingot. The melt starts off with a shallow pool. After a few hours of melting, the pool approaches a quasi-steady state. This quasi-steady profile was used as a basis for validation. Several $0.5 \mathrm{~m}$ alloy 718 ingots were melted over a wide range of current settings to force a variation in steady state melt rate. The pool was marked at current levels of $5 \mathrm{kA}, 6 \mathrm{kA}, 7.3 \mathrm{kA}$ and $8.6 \mathrm{kA}$ [9]. The VAR ingot was sectioned and the center longitudinal slice macro-etched to reveal the pool shape. Simulations were then carried out using the macro melting parameters of these experiments as input to the model. Necessary thermo-physical properties of alloy 718 were obtained from literature [12,13]. In the following sections, modeling and experimental results from these trials are presented. Since the model is two-dimensional axi-symmetric (no angular dependence), all simulations were carried out for an ingot geometry of $0.254 \mathrm{~m}$ in radius and 1.016 $\mathrm{m}$ in height using 30 grid points in the radial direction and 120 grid points in the axial direction. For the purposes of brevity, results of only $6 \mathrm{kA}$ and $8.6 \mathrm{kA}$ are discussed below.

\section{Pool Profile at a Current of $6 \mathrm{kA}$}

The experimentally determined steady state pool at an applied current of 6kA is shown in Figure 3 along with the computed pool profile, superposed on the center longitudinal ingot macrostructure. As seen, the predicted pool profile is in good agreement with the experimentally determined pool.

Figure 4 shows the predicted temperature distribution and molten metal flow in the ingot during VAR. The pool depth at the center is $0.165 \mathrm{~m}$ and the pool is "bowl" shaped. The flow in the molten metal is up along the axis (clockwise). This is typical of buoyancy driven flows. The maximum velocity in the pool is about $0.01 \mathrm{~m} / \mathrm{sec}$. The maximum solidification time, which is the time the center of the ingot spends between the liquidus $(1623 \mathrm{~K})$ and solidus temperature $(1473 \mathrm{~K})$, is about 2520 seconds $(\sim 42$ minutes).

During VAR, only a fraction of the applied current actually enters the ingot. The balance (arc current) passes directly from the crucible to the electrode and so does not influence the liquid metal flow in the VAR pool. Experiments [14,15] have shown this fraction ranges between $50 \%$ and $75 \%$ for $0.5 \mathrm{~m}$ alloy 718 . The current that enters the ingot does so at the meniscus (pool surface) and through the copper plate at the bottom of the ingot. These current flow paths are shown in Figure 1. The computed current distribution in a $0.5 \mathrm{~m}$ VAR ingot at $6 \mathrm{kA}$ is shown in Figure 5-a. The current fraction chosen for the $6 \mathrm{kA}$ simulation was 0.50 . Thus, $3 \mathrm{kA}$ enters the ingot and $3 \mathrm{kA}$ pass directly to the electrode. The model distributes the $3 \mathrm{kA}$ entering the ingot as $0.8 \mathrm{kA}$ entering through the ingot bottom and $2.2 \mathrm{kA}$ entering at the meniscus, based on the imposed boundary condition at the ingot surface. This balance of bottom-to-meniscus current changes as the ingot grows with and more current entering at the meniscus, thus altering the current distribution within the ingot [16]. The current entering at the meniscus is concentrated within the top $0.04 \mathrm{~m}$ of the ingot. Beyond this, the ingot pulls away from the crucible breaking electrical contact at the surface [14, 15].

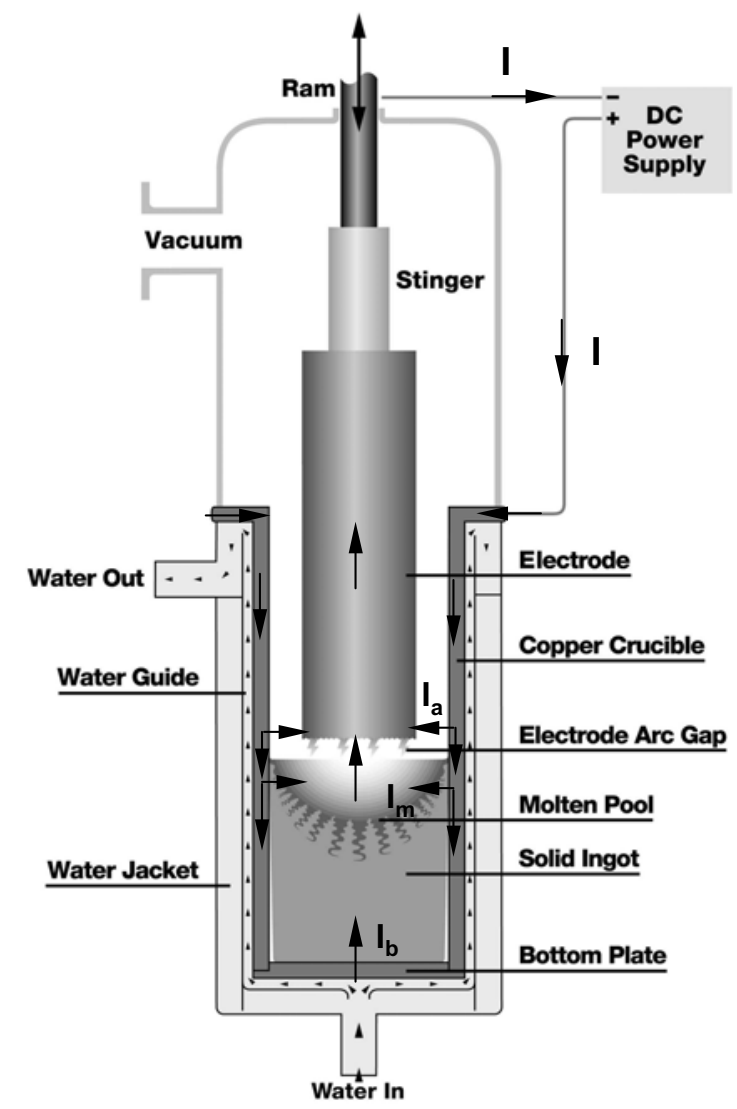

Figure 1: A schematic of the VAR process including the important current flow paths. I is the total applied current, $I_{a}$ is the arc current, $\mathrm{I}_{\mathrm{m}}$ is the meniscus current, and $\mathrm{I}_{\mathrm{b}}$, is bottom current.

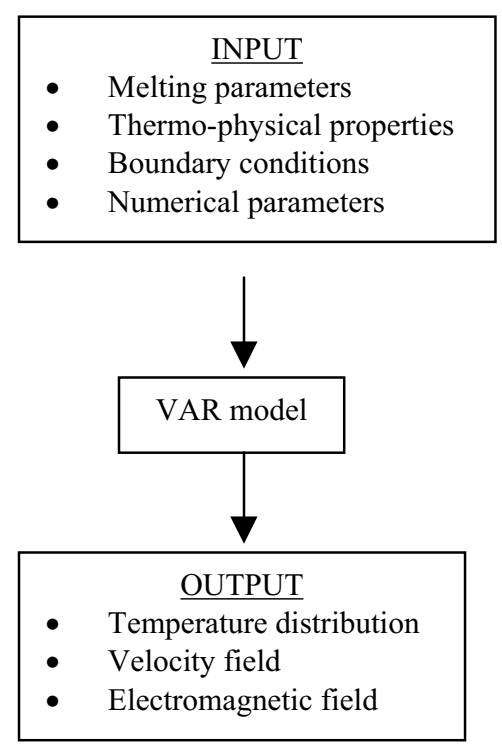

Figure 2: VAR Model setup, showing the different input and output parameters. 


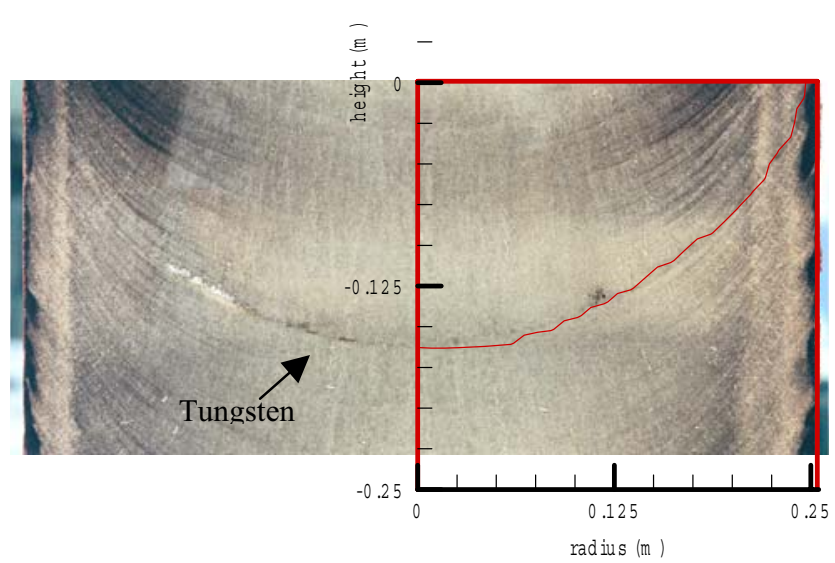

Figure 3: Comparison between predicted and measured pool profile during VAR of a $0.5 \mathrm{~m}$ (20-inch) diameter alloy 718 ingot at $6 \mathrm{kA}$. Tungsten disks were used to mark the pool. Electrolytic etch.

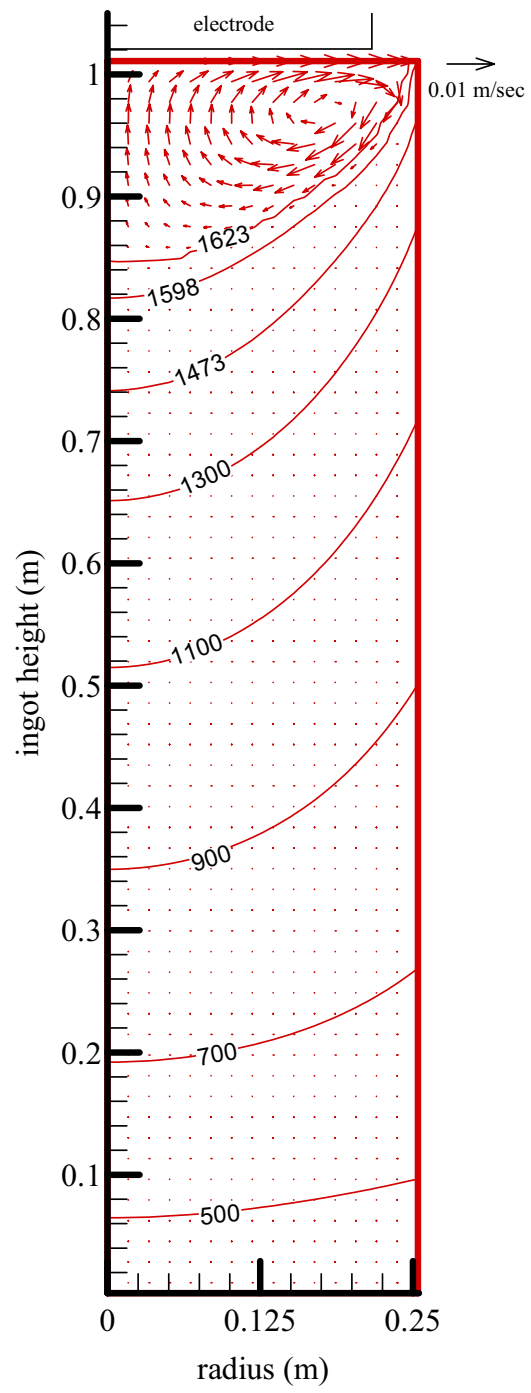

Figure 4: The computed temperature distribution in the ingot and the flow in the molten pool at $6 \mathrm{kA}$.
Thus, except for the very top $0.04 \mathrm{~m}$ of the ingot, the current is predominantly in an axial direction.

The calculated electromagnetic (EM) force field is shown in Figure 5-b. The EM force results from the interaction between the current within the ingot and its associated magnetic field. The maximum force occurs at the top of the ingot, and is about 100 $\mathrm{N} / \mathrm{m}^{3}$. The location of the maximum force depends on the imposed boundary condition on top of the ingot; in most cases, for a Gaussian current distribution, the maximum force occurs at the mid-radius. The EM force decreases by an order of magnitude below the contact zone at the surface of the ingot, and the force is only in the radial direction.

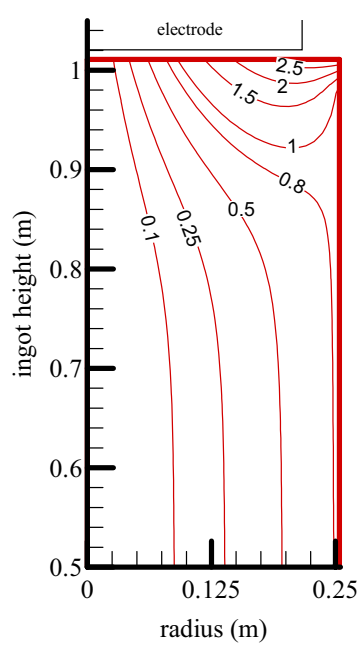

(a)

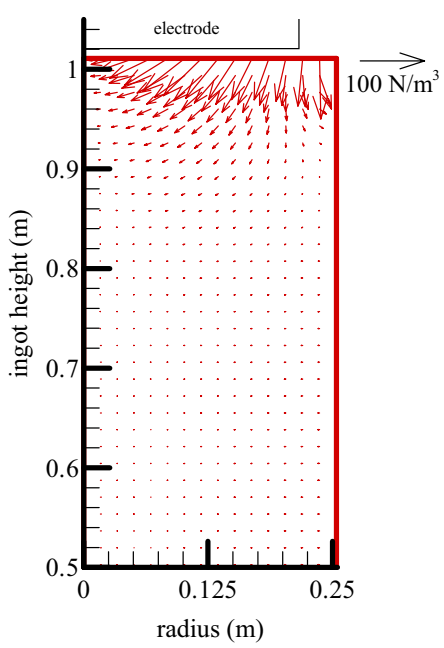

(b)
Figure 5: Current distribution (kA) and electromagnetic force field in a $0.5 \mathrm{~m}(20$-inch) alloy 718 ingot. Of the applied current of $6 \mathrm{kA}$, only $3 \mathrm{kA}$ enters the ingot. Note that the field values of only the top half of the ingot are shown.

Another approximate method of confirming the model predictions is comparing the predicted secondary arm spacing (SDAS) to the measured spacing taken directly from the ingot. This was done using the following relationship [17],

$$
S D A S=\mu t^{1 / 3}
$$

where the parameter $\mu$ for alloy 718 is about $9.4 \times 10^{-6}$ micrometers $/ \mathrm{sec}^{1 / 3}, t$ is the solidification time in seconds and SDAS is in micrometers. From equation (1), the estimated SDAS at an applied current of $6 \mathrm{kA}$ is $130 \mu \mathrm{m}$, which is within $10 \mu \mathrm{m}$ of the measured SDAS at the center of the ingot.

\section{$\underline{\text { Pool Profile at a Current of 8.6kA }}$}

The measured and computed pool profiles at $8.6 \mathrm{kA}$ are shown in Figures 6 and 7. The pool is deep, with a depth of $0.35 \mathrm{~m}$ at the center of the ingot. The flow is still mainly buoyancy driven with a maximum velocity of $0.01 \mathrm{~m} / \mathrm{sec}$, although the flow diminishes considerably at the ingot top. This is due to the larger opposing 


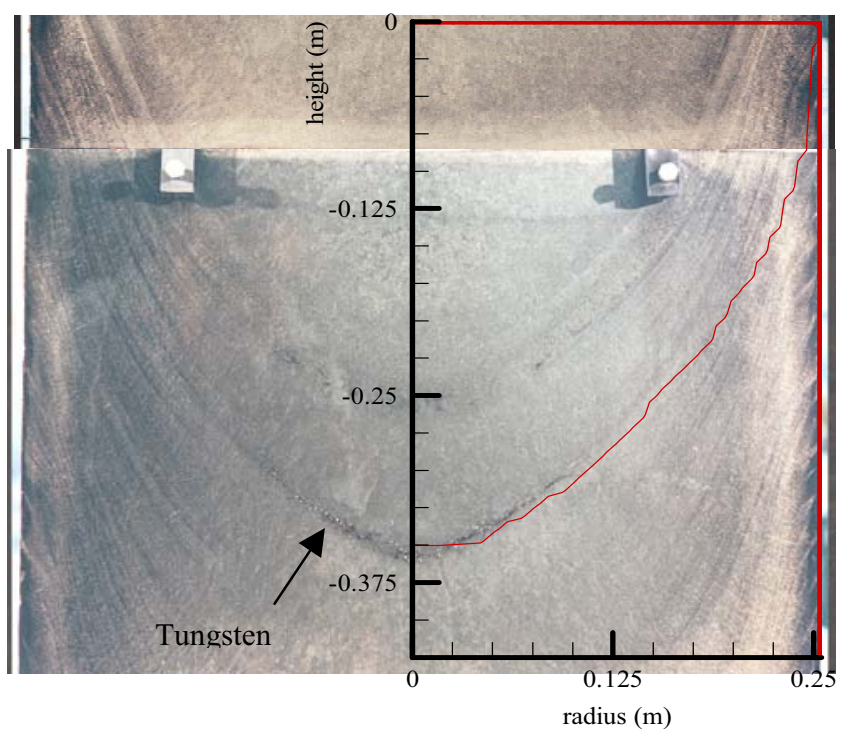

Figure 6: Comparison between predicted and measured pool profile during VAR of a $0.5 \mathrm{~m}$ (20-inch) diameter alloy 718 ingot at $8.6 \mathrm{kA}$

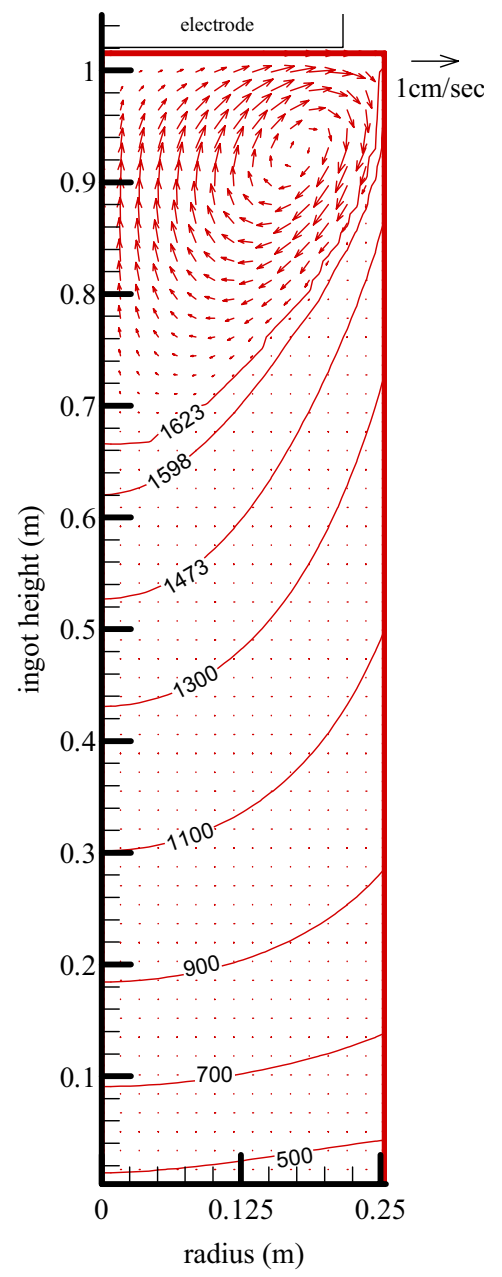

Figure 7: The computed temperature distribution in the ingot and the flow in the molten pool at $8.6 \mathrm{kA}$. electromagnetic force at the top of the ingot. The current flow pattern is shown Figure 8-a. In this case, the contact zone at the meniscus is larger and extends to about $0.12 \mathrm{~m}$ from the top of the ingot. Due to the increased current entering the ingot, maximum electromagnetic force is about $450 \mathrm{~N} / \mathrm{m}^{3}$ as shown in Figure 8-b.

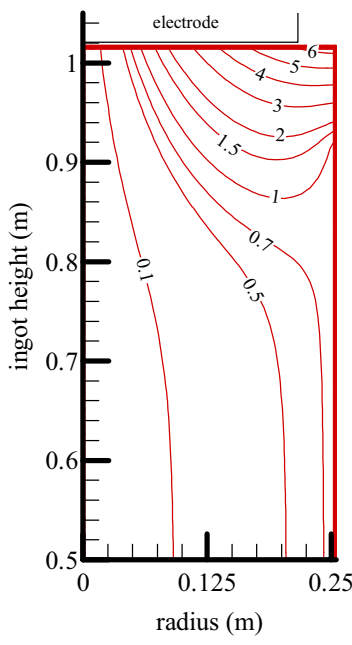

(a)

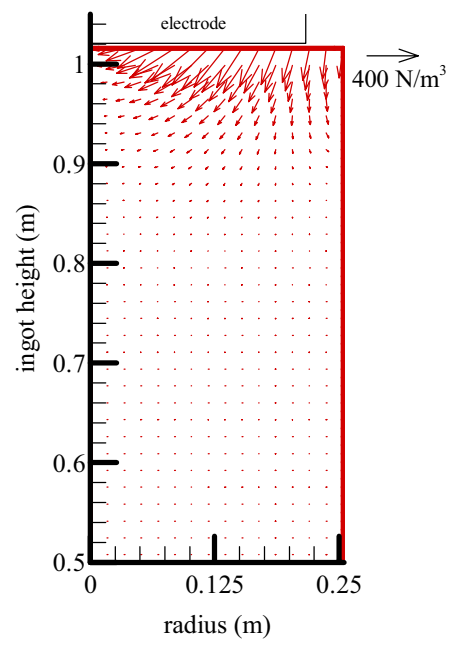

(b)
Figure 8: Current distribution $(\mathrm{kA})$ and electromagnetic force field in a $0.5 \mathrm{~m}$ (20-inch) alloy 718 ingot. Of the applied current of 8.6 $\mathrm{kA}, 6.45 \mathrm{kA}(75 \%)$ enters the ingot in this case. The current entering from the bottom of the ingot is $0.75 \mathrm{kA}$.

\section{Transients During Steady-state Melting}

In the previous sections, the model predictions were validated against a large range of operating currents. The model can now be used to examine the effects of various processing parameters and rapid transients during VAR. During the steady-state portion of the VAR melt, two transients that have been known to occur are power interruptions, or melt rate cycles caused by cracks in the electrode. Changes to the pool during both these transients are examined using the model with $0.5 \mathrm{~m}$ alloy 718 ingot melting at a nominal current of $6 \mathrm{kA}$.

\section{Parameters Affecting the Melt Pool}

During VAR, variation in parameters like electrode diameter, helium pressure, current fraction into the ingot, and arc focus can alter the pool depth. In a constant current VAR practice, an increase in electrode diameter will result in a lower melt rate. This will, in turn, decrease the pool depth, and vice-versa. Experimental studies on $0.21 \mathrm{~m}$ diameter ingots have shown that helium pressure in the gap between the ingot and crucible can also have a significant effect on the pool depth [18]. To examine the effect of these parameters on the pool depth, simulations were carried out using the validated mathematical model. Parameters having similar effects were combined to give a maximum estimate on their likely effect on the pool. Figure 9 shows the expected range of variation of pool depth at the center of a $0.5 \mathrm{~m}$ alloy 718 VAR ingot. Results show that, at each current level, the pool depth can vary by approximately $\pm 0.032 \mathrm{~m}(1.25 \mathrm{inch})$ and the pool depth varies linearly with current. The pool depth to operating current relationship in Figure 9 can be expressed as, 
where: $P_{d}$ is the pool depth at the center of the ingot, and I is the applied current.

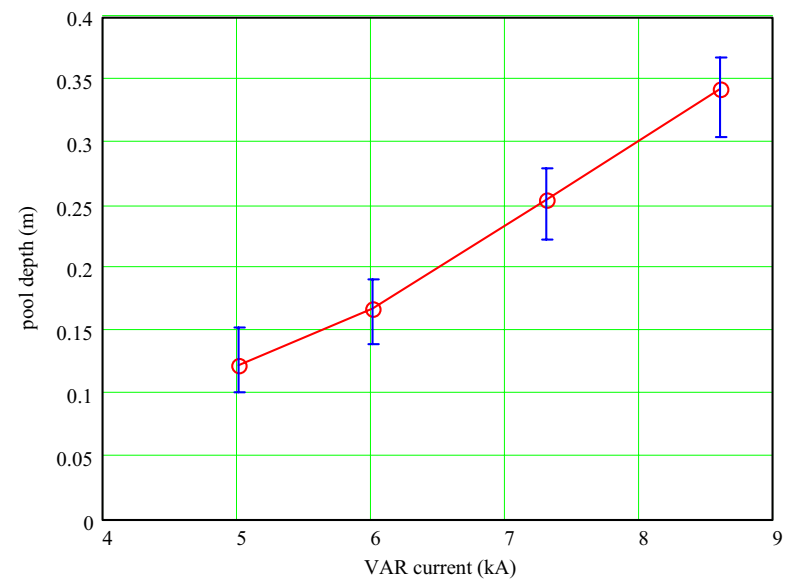

Figure 9: Effect of applied current on pool depth during VAR of a $0.5 \mathrm{~m}$ alloy 718 ingot. The circles denote the measured pool depth, whereas the error bars represent the predicted range of variation of the pool depth.

\section{$\underline{\text { Power Interruption }}$}

Figure 10 shows the changes to the pool during a 5-minute power interruption. In this Figure, $\mathrm{t}=0 \mathrm{sec}$ corresponds to the time of the abrupt power shut-off. The current and melt rate before and after the power interruption were set to their steady-state values. The changes to the molten metal pool (liquidus isotherm) are shown in the contour plot. Essentially, the pool freezes within 3-4 minutes of the power loss. It takes about 15 minutes for the pool depth to return to within $5 \%$ of its nominal value (before the interruption) after the arc is restored. The decrease in thermal gradient due to the power interruption could result in a fine band of equiaxed grains marking the pool [19].

\section{$\underline{\text { Melt Rate Cycle }}$}

Another process disruption that occurs during the steady state is when the melt zone approaches a transverse crack in the electrode. During constant current VAR, as the melt zone approaches the crack, the melt rate increases as the electrode below the crack heats up due to the fact that the crack acts as a barrier to heat flow. This also means the portion of the electrode above the crack is not preheated to the same extent as the material below the crack and is colder. This results in a decrease in melt rate as soon as the melt zone passes through the crack. A representative, hypothetical melt rate profile under such a situation is shown in Figure 11. All values are normalized with respect to nominal values prior to the crack. In this figure, time $\mathrm{t}=0$ is the time when the melt rate just starts to increase. The model predicts that during such a cycle, where the melt rate changes by $\pm 30 \%$, the pool depth increases by only $10 \%$. The pool profiles at the start $(\mathrm{t}=0)$, at the maximum melt rate location $(t=4500 \mathrm{sec})$, and after the event $(t=7200 \mathrm{sec})$ are also shown. The changes to the pool volume are minimal.
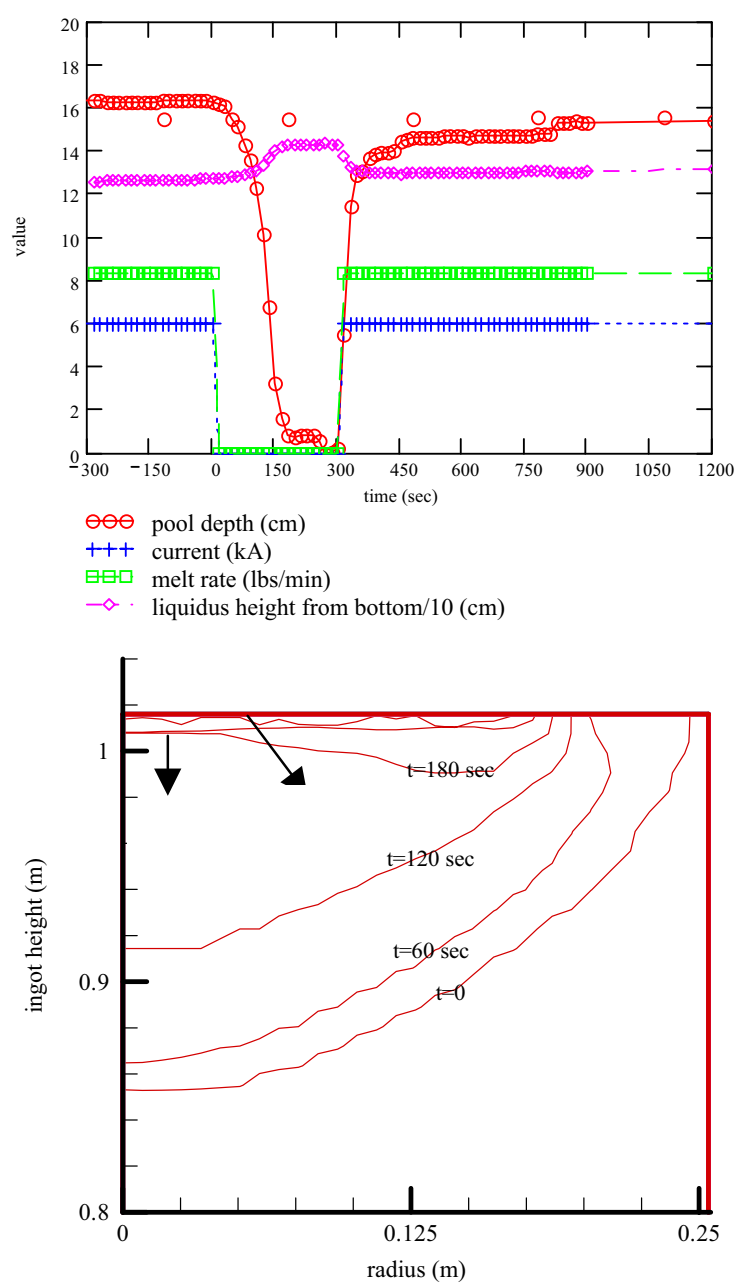

Figure 10: Calculated pool profile during a 300 second power interruption for VAR of a $0.5 \mathrm{~m}$ alloy 718 ingot at $6 \mathrm{kA}$. The power interruption is at $\mathrm{t}=0 \mathrm{sec}$. The melt rate, current, pool depth and the liquidus depth from the bottom of the ingot are shown above.

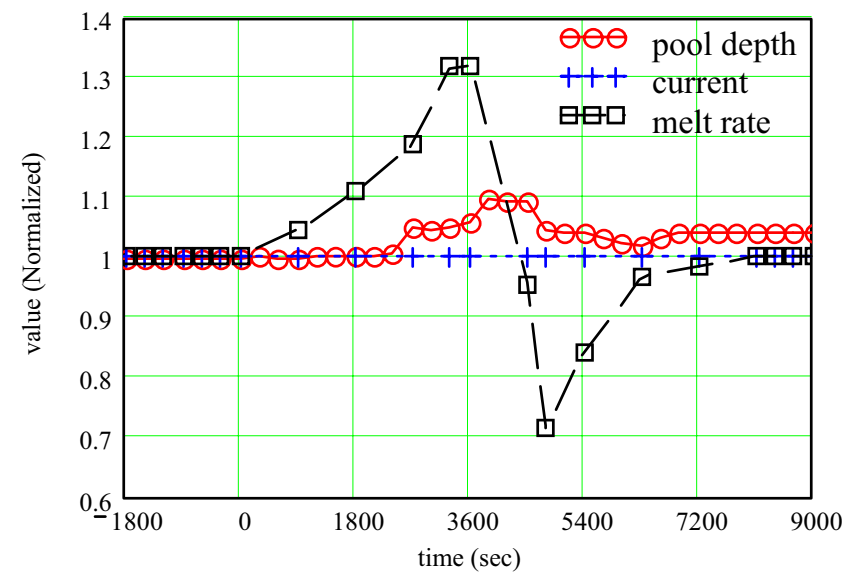

Figure 11: Pool depth variation during a crack type event during VAR of a $0.5 \mathrm{~m}$ alloys 718 ingot. 


\section{Defect Prediction}

In this section, the modeling results are used to predict the likelihood of defects in the ingot. The predicted temperature and flow fields in the molten pool are used to estimate the melting time of particles that fall into the pool during VAR using a simple analytical model. The pool shape and depth is used to determine the likelihood of freckle formation within the ingot using a scaling analysis.

\section{Melting of a Particle within the Melt Pool}

Exogenous defects due to a particle falling into the molten metal pool are inherent to any melting process. In the case of the VAR process, particles can fall into the melt pool from either the electrode or the surface of the ingot. These could either melt completely or partially depending on their size and the melting conditions. The un-melted particles, usually a few millimeters in size, end up as discrete white spots and are usually seen at the center to mid-radius location in the billet [20].

For a particle of $5 \mathrm{~mm}$ radius, the time scale, $\mathrm{t}_{\mathrm{m}}$, for melting is:

$$
t_{m}=\frac{\left(P_{d}^{2}+R^{2}\right)^{1 / 2}}{v_{p}}
$$

where: $P_{d}$ is the pool depth at the center of the ingot, $R$ is the radius of the ingot, and $v_{p}$, is the settling velocity. Using Stokes law, and a drag coefficient of 0.44 , the settling velocity of the particle is in the range of $8-10 \mathrm{~cm} / \mathrm{sec}$. Thus, for a $17 \mathrm{~cm}$ pool depth $(6 \mathrm{kA})$ and a $25.4 \mathrm{~cm}$ ingot radius, the time scale for the particle to settle to the bottom of the pool is 3 to 4 seconds at most. Hence, within a short time of entering the pool, the particle reaches the bottom of the pool. Also, since these particles typically are lean in solute, they have a higher melting temperature. Once they reach the pool bottom, melting ceases and the moving solidification front eventually entraps the particle.

The melting rate of particles in molten metal has been extensively studied in the context of dissolving alloying elements in steel making $[20,21]$. The same basic formulation is used here. As the particle falls in, its surface is heated to the liquidus temperature prior to melting. The problem essentially reduces to determining transient temperature within the particle with a moving interface at the surface of the particle. An analytical solution is obtained using the heat-balance integral technique [23] employing a fourth order polynomial approximation for the temperature distribution in the particle. The particle melting kinetics and dissolution during VAR has also been studied using numerical models $[24,25]$.

Figure 12-a shows the melting of a $5 \mathrm{~mm}$-radius particle dropped into the melt from the surface of the ingot. Assuming that the particle is at $150 \mathrm{~K}$ below the liquidus temperature, the particle size reduces to about $1 \mathrm{~mm}$ in 4 seconds. However, if the initial particle temperature is $250 \mathrm{~K}$ below the liquidus temperature, its size is nearly $3 \mathrm{~mm}$ within 4 seconds. The model shows that it takes between 4.75 to 7.75 seconds for a $5 \mathrm{~mm}$-radius particle to completely melt. The melting kinetics for a $15 \mathrm{~mm}$ radius particle are shown in Figure 12-b. Due to the larger size, the time scale to reach the bottom of the pool is reduced to 2.25 seconds, which, in this case is comparable to the time for preheating the particle to the liquidus temperature. The predicted time to completely melt these larger particles is in the range of 40 to 70 seconds, which is consistent with the predictions of the numerical model of Erdeljack et al. [24].

It should be noted that, in this analysis, niobium diffusion from the molten pool into the particle is neglected. Using the analogy between mass and heat transfer, the mass transfer coefficient is about $10^{-4} \mathrm{~m} / \mathrm{sec}$, and a mass balance at the surface of the particle estimates an increase in niobium of up to $0.5 \mathrm{wt} \%$ at the surface within the melting time scale.

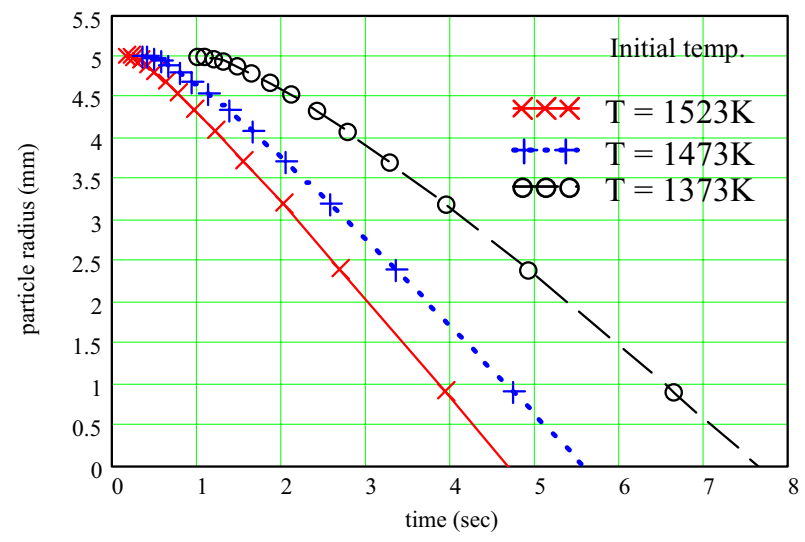

(a)

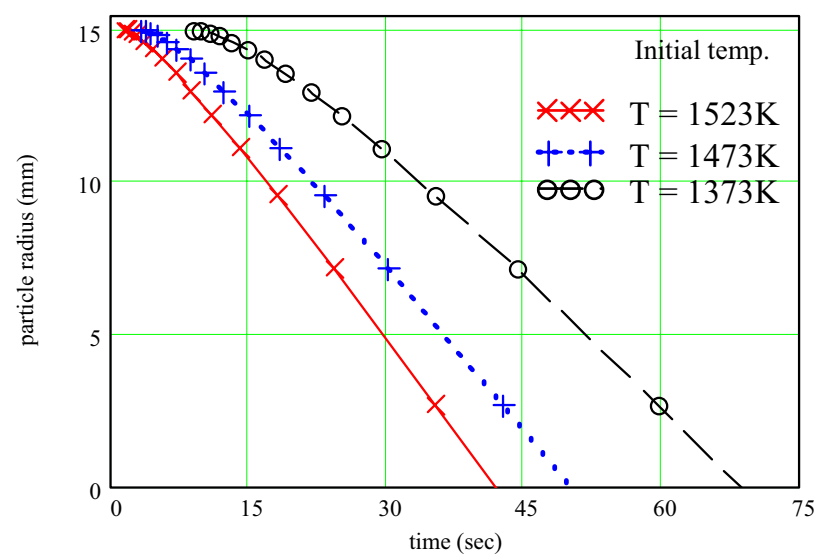

(b)

Figure 12: Melting of a particle falling into the melt pool during VAR of a $0.5 \mathrm{~m}$ alloy 718 ingot. The initial radius of the particle falling into the pool is $5 \mathrm{~mm}(12-\mathrm{a})$ and $15 \mathrm{~mm}(12-b)$. The initial temperature of the particle is taken to be 100,150 and $250 \mathrm{~K}$ below the liquidus.

\section{$\underline{\text { Freckle Criteria }}$}

It is well known that higher current levels during VAR of alloy 718 significantly increase the likelihood of freckle formation in the ingot [8]. Results presented earlier clearly show that, at low current levels, the pool is shallow, and as the applied current increases, the pool gets deeper. The longitudinal macrostructure of a freckled ingot usually shows dark bands along the pool 
(normal to the columnar grains). The bands originate around the mid-radius location, extend $1-5 \mathrm{~cm}$ towards the ingot center, and are usually very narrow, $2-5 \mathrm{~mm}$ in thickness [26].

Over the years, different criteria for freckle formation in the VAR process have been proposed [27, 28]. These criteria are essentially based on a critical mushy zone size and thus a maximum local solidification time beyond which freckling occurs in the ingot. Recently, criteria involving the Rayleigh number have been proposed based on the studies in the area of directional solidification [29-31]. The Rayleigh number ( $\mathrm{Ra})$, which is the ratio of buoyancy-to-viscous force is defined as:

$$
R a=\frac{\left(\frac{\Delta \rho}{\rho}\right) g K L}{\alpha v}
$$

where: $g$ is gravity, $\rho$ is the liquid density, $\Delta \rho$ is the density change, $\mathrm{K}$ is permeability, $\alpha$ is the thermal diffusivity, $v$ is the kinematic viscosity and $\mathrm{L}$ is the characteristic length scale. The existing theory is that an imbalance of forces initiates interdendritic flow in the mushy zone causing remelting (melt-back) of the solute lean dendrites. This remelting of the dendrites initiates the freckle. In alloy 718 , the freckle propagates along the pool due to the higher density of the niobium rich inter-dendritic liquid [32]. In this analysis density ratio that initiates in the interdendritic flow is approximated from the macro-model as:

$$
\frac{\Delta \rho}{\rho} \approx \beta G L
$$

where, $\beta$ is the thermal expansion coefficient, $G$ is the radial temperature gradient. Since higher current levels during VAR increase the likelihood of freckle formation, the characteristic length scale is taken to be the pool depth.

Figure 13 shows the calculated Rayleigh number across the ingot for the two current levels. The Rayleigh number is maximum at about the mid-radius and it increases with increasing VAR current. Both these characteristics of the Rayleigh number are consistent with the observation that freckle tendency increases with current and that freckles are typically found at about the midradius location in the ingot. At an applied current of $8.6 \mathrm{kA}$, the calculated Rayleigh number is nearly five times that at $6 \mathrm{kA}$. Recently, Suzuki et al. reported freckles in a $0.45 \mathrm{~m}$ (18 inch) diameter VAR ingot melted using a current of 9kA [26]. Using these melting parameters, the critical calculated Rayleigh number appears to be about 200, beyond which the likelihood of freckle formation increases significantly.

\section{Concluding Remarks}

Model predictions are in good agreement with the measured pool for all current ranging from $5 \mathrm{kA}$ to $8.6 \mathrm{kA}$, for a $0.5 \mathrm{~m}$ alloy 718 ingot. As the applied current increases, the pool gets deeper. During VAR, only a fraction of the applied current enters the ingot $(50-75 \%)$. The current enters the ingot at two locations: at the meniscus and through the stool at the bottom of the ingot. Within this range of current, the flow in the pool is predominantly buoyancy drive, with a maximum velocity of $0.01 \mathrm{~m} / \mathrm{sec}$.

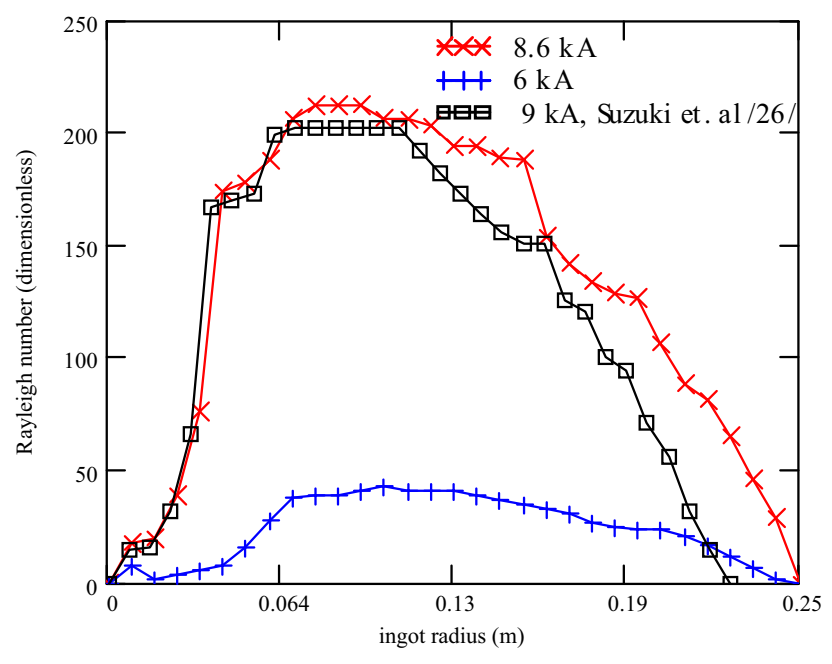

Figure 13: Calculated Rayleigh number for a $0.5 \mathrm{~m}$ diameter VAR ingot at different current levels. The growth rate was determined from the quasi-steady melt rate. Equations for permeability and primary dendrite arm spacing were obtained from literature and were evaluated at $\mathrm{f}_{\mathrm{l}}=0.9 / 29,17 /$.. The expansion coefficient, $\beta=$ $10^{-4} / \mathrm{k}$, kinematic viscosity $v=10^{-6} \mathrm{~m}^{2} / \mathrm{sec}$ and the thermal diffusivity $\alpha=6 \times 10^{-6} \mathrm{~m}^{2} / \mathrm{sec}$.

The pool depth increases linearly with the applied current, and can vary as much as $0.032 \mathrm{~m}$ during the melt. As pool depth increases, the time scale for melting of particles that fall into the pool increases. The time scale for particle melting is relatively short, about 3 to 4 seconds, and the particles with radius less than $4 \mathrm{~mm}$ that fall into the molten pool completely remelt. Larger particles get entrapped by the solidification front and show up as white spots in the billet.

As pool depth increases, likelihood of freckle formation also increases, since the critical Rayleigh number is proportional to the square of the pool depth. Although freckles were not found in this $0.5 \mathrm{~m}$ diameter alloy 718 ingot, using the melting parameters available in literature [26] and this criteria, it appears that during VAR of alloy 718 , in order to cause freckling, the inter-dendritic fluid velocity should exceed its nominal value by at least five times.

Further work is needed in defining model parameters and their interaction with each other. An example is the interaction between nominal current, arc radius, and turbulence scaling factor. The best pool fits in this simulation were accomplished when all three were varied in a coordinated manner with increasing current. Also, more robust defect prediction criteria, based on detailed computation within the mushy zone, are also needed.

\section{Acknowledgements}

The authors would like to thank the Specialty Metals Processing Consortium for providing the platform for collaborative research in the area of modeling and VAR process diagnostics. We would 
also like to thank our colleagues for many constructive comments and discussions of this subject.

\section{References}

1. G. E. Maurer, Superalloys, Supercomposites and Superceramics, ed. Tien and Caulfield, (Academic Press, New York, 1989), 49-97.

2. Specialty Metals Processing Consortium: The Perspective of Industrial Members, JOM, V50 (3), (1998), 26-29.

3. X. Xu. et al., Proc. Liquid Metal Processing and Casting, ed. A. Mitchell, et al, AVS, (1999),76-89.

4. R. M. Ward, et al, Proc. Liquid Metal Processing and Casting, ed. A. Mitchell and J. Van Den Avyle, AVS, (2001),187-199.

5. S. Hans, A. Jardy, and D. Ablitzer., Proc. Liquid Metal Processing and Casting, ed. A. Mitchell, Ridgeway, M. Baldwin, AVS, (1994), 143.

6. Jardy, et al, Proc. Liquid Metal Processing and Casting, ed. A. Mitchell and J. Van Den Avyle, AVS, (2001),200-210.

7. L. A. Bertram, et al., Proc. Liquid Metal Processing and Casting, ed. A. Mitchell, L. Ridgway, M. Baldwin, AVS, (1999), 156-167.

8. L. A. Bertram, R. S. Minisandram, and K. O. Yu, Modeling for Casting and Solidification Processing, ed. K. O. Yu, (2002), 565-612.

9. L. A. Bertram et al., Proc. Liquid Metal Processing and Casting, ed. A. Mitchell, P. Auburtin, AVS, (1997), 110-132.

10. L. A. Bertram, et al., JOM 50 (3), (1998), 18-21.

11. L. A. Bertram and F. J. Zanner, Proc. Modeling of Casting and Welding Processes, ed. H. D. Brody, D. Apelian, TMS, (1981), 333-349.

12. P. N. Quested et al., Proc. Liquid Metal Processing and Casting, ed. A. Mitchell, P. Auburtin, AVS, (1997), 1-17.

13. G. A. Knorovsky et al., Met. Trans., 20A, (1989), 21492158.

14. R. L. Williamson and G. J. Shelmidine, Superalloys 718, 625, 706 and Various Derivatives, ed. E. Loria, TMS, (2001), 91-102.

15. R. M Ward and M. H. Jacobs, Proc. Of Liquid Metal Processing and Casting, ed. P. D. Lee, A. Mitchell, J. Bellot, A. Jardy, (2003), 49-59.

16. A. D. Patel, Proc. Of Liquid Metal Processing and Casting, ed. P. D. Lee, A. Mitchell, J. Bellot, A. Jardy, (2003), 205214.

17. W. Kurz and D. J. Fisher, Fundamentals of Solidification, (Trans Tech Publication Ltd, Switzerland 1998) 80-89.

18. L. G. Hosamani, W. E. Wood and J. H. Devletian, Proc. Of Superalloy 718 Metallurgy and Applications, TMS (1989) 49-57.

19. X. Xu et. al., Met. and Mat. Trans. A., Vol. 33, (2002), 17951804.

20. L. A. Jackman, G. E. Maurer, and S Widge, Advanced Materials \& Processes, Vol. 5, (1993) 18-25.

21. L. Zhang and F. Oeters, Melting and mixing of alloying agents in steel melts, (Verlag Stahleisen GmgH, Dusseldorf, 1999).

22. J. Szekely, Y. K. Chuang, and J. W. Hlinka, Met. Trans., Vol. 3, (1972), 2825-2833.

23. T. R. Goodman, Trans. ASME, V80, (1958), 335-342.
24. J. P. Erdeljac, H. Henein, and A. Mitchell, ISS Trans., Vol. 6, (1985), 51-60.

25. W. Zhang, P. D. Lee, and M. Mclean, Proc. Superalloys 2000, Ed. T. M. Pollock et al., TMS, (2000), 29-37.

26. T. Suzuki et al., Proc. Of Liquid Metal Processing and Casting ed. A. Mitchell and J. Van Den Avyle, AVS, (2001), 325-337.

27. K. O. Yu et al., JOM, Vol. 1 (1986), 46-50.

28. P. Auburtin and A. Mitchell, Proc. Liquid Metal Processing and Casting, ed. A. Mitchell, P. Auburtin, AVS, (1997), 1834.

29. S. D. Felicelli, D. R. Poirier, and J. C. Heinrich, Met. and Mat. Trans. B, Vol 29, (1998), 847-855.

30. P. Auburtin et al., Met. and Mat. Trans. B, vol. 31, (2000), 801-811.

31. W. Yang et al., Met. and Mat. Trans. A, vol. 32, (2001), 397406.

32. J. Van Den Avyle, J. A. Brooks, and A. C. Powell, JOM, V50 (3), (1998), 22-25. 